\title{
Analysis of tailings beach slopes based on slurry pipeline experience
}

\author{
A. Thomas Slurry Systems Pty Limited, Australia \\ T.G. Fitton ATC Williams Pty Ltd, Australia
}

\begin{abstract}
Slurry pipeline technology has evolved over the past 50 years and prediction methods for all types of slurries, ranging from coarse solids in water to highly non-Newtonian slurries, are reasonably well developed. In comparison, prediction methods for tailings flow down a beach and the resulting beach slope, are less well developed although the two types of flow are obviously related to some extent.
\end{abstract}

The current paper analyses open channel flow down a tailings beach using approaches developed for pipe flow. Predictive slope equations are presented. The resulting predicted slopes are compared with a range of measured slopes in both flume experiments and tailings deposit slopes at a number of operating mines.

\section{Introduction}

Pressurised pipeline flow occurs due to a pressure gradient (or head loss gradient) applied either by a pump or by a gravity head difference. The larger the pump head or gravity head, the higher the flow rate. Open channel flow occurs due to a head loss gradient resulting from the slope of the channel - the higher the slope, the higher the flow rate. For water flows, both pipe and open channel flows have been studied for centuries. Open channel flow of water in erodible channels, such as rivers, has also been studied for more than a century. Serious study of pipe flow of granular solids in water began about 60 years ago.

Modern large scale mining and associated wet grinding and processing, produces large quantities of slurry with a wide particle size distribution, including some very fine particles. This results in tailings slurries which possess viscous, non-Newtonian, properties. The non-Newtonian nature of these tailings slurries separates mine tailings flow behaviour, both in pipes and on beach slopes, from the traditional sand in water pipe flow and open channel flow in erodible channels.

Tailings are typically discharged into a tailings storage facility (TSF) as a slurry. The solids settle out to form a sloping deposit, which is referred to as a beach. As more tailings slurry is discharged, it typically flows down the beach in a confined channel. It has been shown that the slope of a tailings beach is dictated by the slope that this channel assumes (Williams and Meynink, 1986; McPhail, 1994; Fitton, 2007). Therefore, the key to predicting tailings beach slopes is to predict the slope of the self formed channel.

In recent years the scale of mining has expanded tremendously, with larger mines now processing 100,000200,000 tpd of ore. In metalliferous mines the majority of the ore mined ends up as finely ground tailings which have to be pumped to a TSF and then discharged to flow down a self formed beach slope. The primary aim of the current paper is to apply methods developed for predicting tailings pipe flow to predicting beach slopes.

\section{Slurry pipeline flow behaviour and prediction methods}

\subsection{Typical pipe flow behaviour}

Figure 1 shows head loss gradient versus velocity logarithmic plots (Thomas, 1974) from loop tests in a $105 \mathrm{~mm}$ ID pipe for a loam slurry consisting of a mixture of sand $\left(\mathrm{d}_{80}=0.5 \mathrm{~mm}\right)$ and clay. The percent ratio of sand to clay was about 80:20 by weight. Although typical tailings slurries have a significantly finer top size and a more continuous size distribution than this loam slurry, the behavioural changes as concentration varies, are similar. 


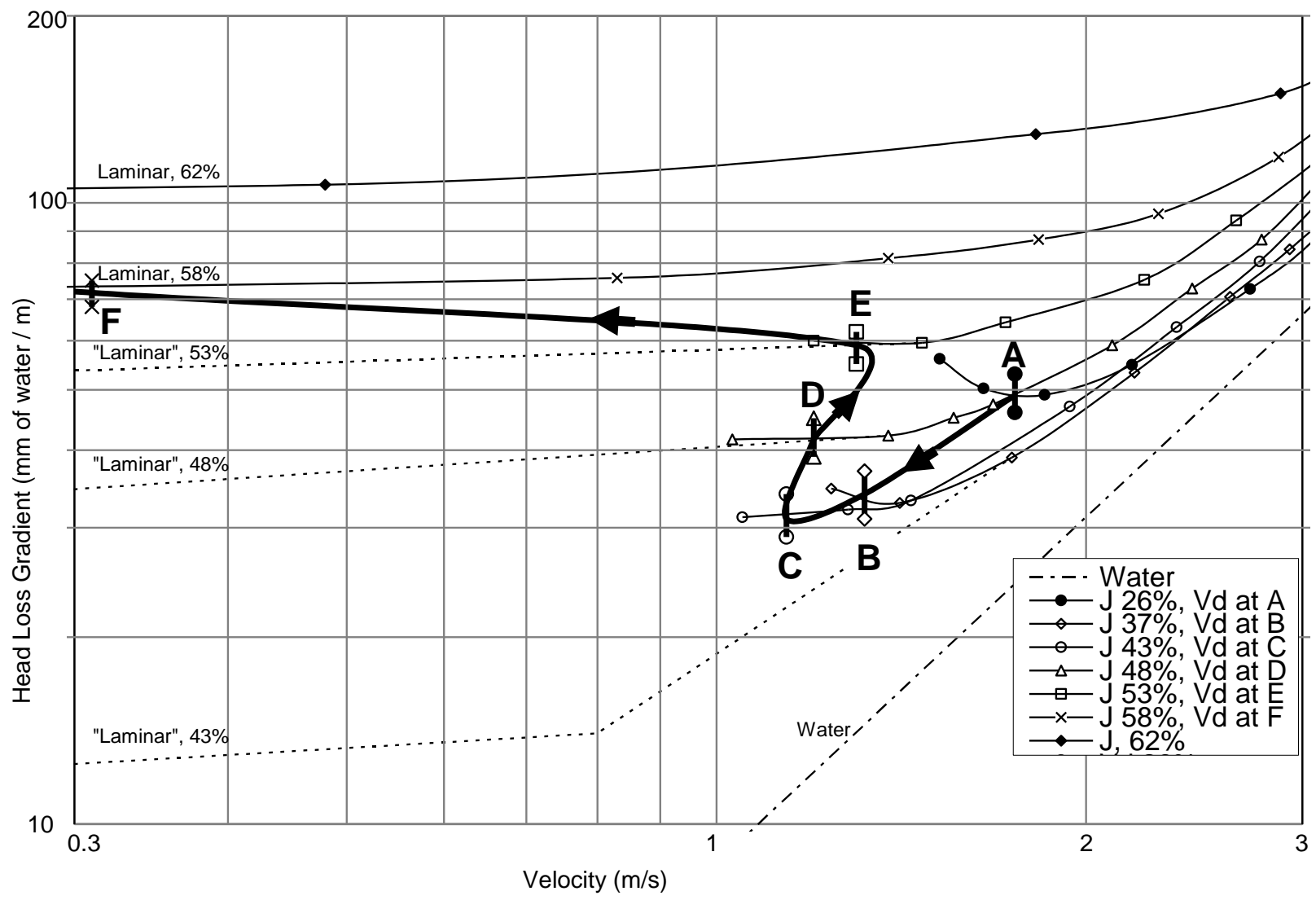

Figure 1 Test loop results for loam slurry in $105 \mathrm{~mm}$ pipe

The vertical bars at $\mathrm{A}, \mathrm{B}, \mathrm{C}, \mathrm{D}, \mathrm{E}$ and $\mathrm{F}$ indicate deposit velocities with the deposit velocity being the velocity below which a stationary bed of solids was observed in the pipe. Point A indicates the $1.75 \mathrm{~m} / \mathrm{s}$ deposit velocity for the lowest solids weight concentration of $26 \%$. As the concentration is increased to $37 \%$, the higher viscosity of the slurry combined with the reduced ratio of solids density to slurry density, causes the deposit velocity to decrease to $1.32 \mathrm{~m} / \mathrm{s}$ (Point B). Further increase in concentration to $43 \%$ causes a further decrease in the deposit velocity to $1.14 \mathrm{~m} / \mathrm{s}$ (Point C). The reduction in deposit velocity from A to B to $\mathrm{C}$ is explained by turbulent heterogeneous deposition criteria. The deposit velocity in turbulent heterogeneous flow is a function of particle size, solids SG, concentration and viscosity. Note that as the deposit velocity decreases from $\mathrm{A}$ to $\mathrm{C}$, the head loss gradient at deposition decreases from $50 \mathrm{~mm}$ water $/ \mathrm{m}$ to $30 \mathrm{~mm}$ water/m.

Point C represents about the lowest deposition velocity for this slurry. Thomas (1979a) observed that as the particle size of sand particles in water is continuously decreased, the turbulent deposit velocity reaches a lower limit, typically around $0.5 \mathrm{~m} / \mathrm{s}$ for sand in water. Further reduction in particle size does not result in any further reduction in deposit velocity. At this stage the fine particles flow homogeneously, without heterogeneity, but still deposit out. Thomas developed a theory for this homogeneous turbulent flow deposition based on deposition within the viscous sub-layer which occurs when the turbulent viscous sublayer becomes thick enough to trap particles, even though the same particles can be supported by turbulence in the core region. The deposition Point $\mathrm{C}$ for $43 \%$ concentration slurry in Figure 1 probably represents viscous sub-layer deposition.

In Figure 1, the lower dashed curve on the left denoted "Laminar" 43\% represents the head loss gradient which would occur at low velocities at $43 \%$ concentration if laminar flow without deposition was possible. For example, this head loss gradient curve would be obtained if the slurry was tested in a vertical pipe where settling was not an issue. Note in this case the transition to turbulent flow at $0.8 \mathrm{~m} / \mathrm{s}$ as evidenced by the sudden change in slope to more closely parallel the water curve. However, in the horizontal pipe deposition has occurred at $1.14 \mathrm{~m} / \mathrm{s}$ (Point C) under turbulent flow conditions before transition is reached. 
When the concentration is increased from $43-48 \%$ the laminar flow curve rises up sufficiently that it cuts the turbulent flow curve at around $1.5 \mathrm{~m} / \mathrm{s}$. The intersection of the laminar and turbulent flow curves represents the transition velocity. Although laminar flow therefore occurs below $1.5 \mathrm{~m} / \mathrm{s}$, the head loss gradient is not sufficient to sustain laminar flow without deposition at velocities much below the transition velocity and deposition occurs about $0.3 \mathrm{~m} / \mathrm{s}$ below transition under laminar flow conditions at $1.2 \mathrm{~m} / \mathrm{s}$ (Point D).

A 53\% concentration the laminar curve rises higher and cuts the turbulent flow curve at around $1.8 \mathrm{~m} / \mathrm{s}$, i.e. the transition velocity has increased to around $1.8 \mathrm{~m} / \mathrm{s}$. Once again the head loss gradient is not sufficient to sustain laminar flow without deposition much below the transition velocity and deposition occurs about $0.5 \mathrm{~m} / \mathrm{s}$ below transition under laminar flow conditions at $1.3 \mathrm{~m} / \mathrm{s}$ (Point E).

When the concentration is increased to $58 \%$ the transition velocity increases to around $2.5 \mathrm{~m} / \mathrm{s}$ as evidenced by the change in slope of the actual data curve around this velocity. The head loss gradient is now sufficiently high such that laminar flow without deposition is able to be sustained until deposition occurs under laminar flow conditions at $0.3 \mathrm{~m} / \mathrm{s}$. At the highest $62 \%$ concentration, the head loss gradient has become sufficiently high that no deposition was observed right down to zero flow rate.

Thomas (1979b) was among the first to note that under laminar pipe flow conditions, unless the particles are essentially all colloidal sized, such as in a pure clay slurry, particles will slowly settle as the slurry proceeds along the pipeline because there are no turbulent eddies to keep them suspended. Thus the laminar flow deposit velocities D, E and F in Figure 1 only apply to the particular length of test loop pipeline from the pump discharge to the observation point $(23 \mathrm{~m})$. If the viewing section was located a longer distance from the pump then deposition would have been observed at a higher velocity than $0.3 \mathrm{~m} / \mathrm{s}$ for the $58 \%$ concentration slurry and deposition would probably have occurred for the $62 \%$ concentration case even though no deposition was observed in the $23 \mathrm{~m}$ length of the pipe loop.

Thus, given sufficient pipeline length, under laminar flow conditions most particles will settle to form a sliding bed. It is generally accepted that to prevent stationary bed build up under laminar flow, the pressure gradient must exceed a critical value. Houman and Johnson (2002) set the pressure gradient at about $2,000 \mathrm{~Pa} / \mathrm{m}$ or $200 \mathrm{~mm}$ water/m. Cooke (2002) states between $1,000 \mathrm{~Pa} / \mathrm{m}$ and $2,000 \mathrm{~Pa} / \mathrm{m}$, i.e. between $100 \mathrm{~mm}$ water/m and $200 \mathrm{~mm}$ water/m. In Figure 1 the highest head loss gradient under laminar flow conditions is around $100 \mathrm{~mm}$ water/m, suggesting that the $62 \%$ concentration slurry would probably exhibit deposition if pumped over a longer distance than in this particular test loop. The loam slurry concentration would need to be increased to around $65 \%$ to ensure no deposition occurred over any pipeline length.

In the above discussion the transition velocity was determined by the intersection of the laminar and turbulent head loss gradient curves. Based on their earlier theory (Wilson and Thomas, 1985) of nonNewtonian turbulent flow, Wilson and Thomas (2006) derived the following more direct expression for the transition velocity of a Bingham plastic slurry.

$$
\mathrm{V}_{\mathrm{t}}=25\left(\tau_{\mathrm{y}} / \rho_{\mathrm{sl}}\right)^{0.5}
$$

A similar expression had been presented earlier by other workers based on a Reynolds number transition approach. Note that Equation (1) is independent of pipe diameter and so should also apply to open channel flow of any width.

\subsection{Turbulent flow heterogeneous deposition in pipes}

Durand (1953) was the first to provide an expression for the deposit velocity. His classic equation was based on extensive tests on sand water suspensions in a range of pipe sizes. It is a testament to his work that his equation is still used today by many workers, although, as explained further, it should not be used directly for tailings slurries.

The Durand expression for deposit velocity states that the deposit velocity, $\mathrm{V}_{\mathrm{d}}$, varies with the square root of pipe diameter for all particle sizes. Wilson and Judge (1976) developed a theory to extend the Durand equation to finer sand particles. Their theory shows that the exponent of pipe diameter $\mathrm{D}$ is not a constant 0.5 but decreases as the particle size decreases.

Thomas (1979a) provided a graph of deposit velocity versus pipe diameter based on the theory of Wilson and Judge (1976) and incorporating the lower limit of viscous sub-layer deposition discussed previously. This 
graph is reproduced as Figure 2. For present purposes power law approximations have been fitted as per Equation (2) to the curves and are shown as dashed lines. The particle sizes on the right refer to the $\mathrm{d}_{50}$ size.

$$
\mathrm{V}_{\text {dhet }}=\mathrm{A}^{\prime} \mathrm{D}^{\mathrm{n}}
$$

In Figure 2, the exponent $\mathrm{n}$ ranges from 0.58 for $\mathrm{d}_{50}=0.5 \mathrm{~mm}$ and coarser to 0.11 at the lower limit of $\mathrm{d}_{50}=0.025 \mathrm{~mm}$.

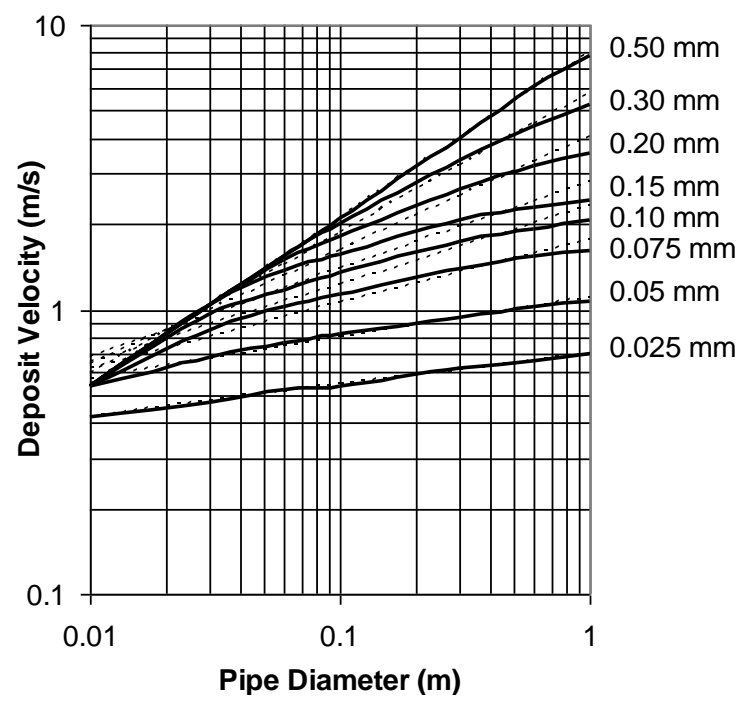

Figure 2 Deposit velocities for narrow size sands in water

A and $n$ are functions of $d_{50}$, but to generalise more, predicted particle settling velocities for equivalent $d_{50}$ size spheres have been determined for each of the eight $\mathrm{d}_{50}$ sizes in Figure 2 . $\mathrm{A}^{\prime}$ and $\mathrm{n}$ for each size were then plotted against settling velocity $\mathrm{V}_{0}$ and power law equations fitted. A' has also been generalised further to allow for differing solids and water SGs. The resulting equations to predict deposit velocity in pipes are:

$$
\begin{gathered}
\mathrm{V}_{\text {dhet }}=\mathrm{A} \mathrm{D}^{\mathrm{n}} \\
\mathrm{A}=25.71\left[\left(\rho_{\mathrm{s}}-\rho_{\mathrm{w}}\right) / \rho_{\mathrm{w}} / 1.65\right]^{0.5} \mathrm{~V}_{0}{ }^{0.50} \\
\mathrm{n}=1.42 \mathrm{~V}_{0} 0.35
\end{gathered}
$$

Since the tailings slurries of interest are generally relatively fine and usually possess a viscosity at least three or four times that of water particle settling, it is assumed to be described by the Stokes equation for a sphere.

$$
\mathrm{V}_{0}=\mathrm{g} \mathrm{d}^{2}\left(\rho_{\mathrm{s}}-\rho_{\mathrm{w}}\right) / 18 / \eta_{\mathrm{pl}}
$$

For a wide size distribution slurry the relevant particle size, $d$, is the weighted mean particle size obtained by splitting the size distribution into fractions and summing the products of the median size in each fraction by the fractional mass in that fraction.

The Wilson and Judge (1976) theory upon which Figure 2 is based, was developed for narrow size distribution sands. Similar trends occur for wide size distribution slurries as is illustrated in Figure 3 which shows observed deposit velocity ranges for a wide size distribution sand $\left(\mathrm{d}_{80}=0.40 \mathrm{~mm}, \mathrm{~d}_{50}=0.18 \mathrm{~mm}\right.$, $\mathrm{d}_{20}=0.06 \mathrm{~mm}$ ), and iron ore $\left(\mathrm{d}_{80}=0.08 \mathrm{~mm}, \mathrm{~d}_{50}=0.03 \mathrm{~mm}, \mathrm{~d}_{20}=0.008 \mathrm{~mm}\right.$ ), as per Schriek et al. (1973a, $1973 \mathrm{~b}$ respectively). The slope (n) for the sand is 0.60 and for the iron ore 0.17. 


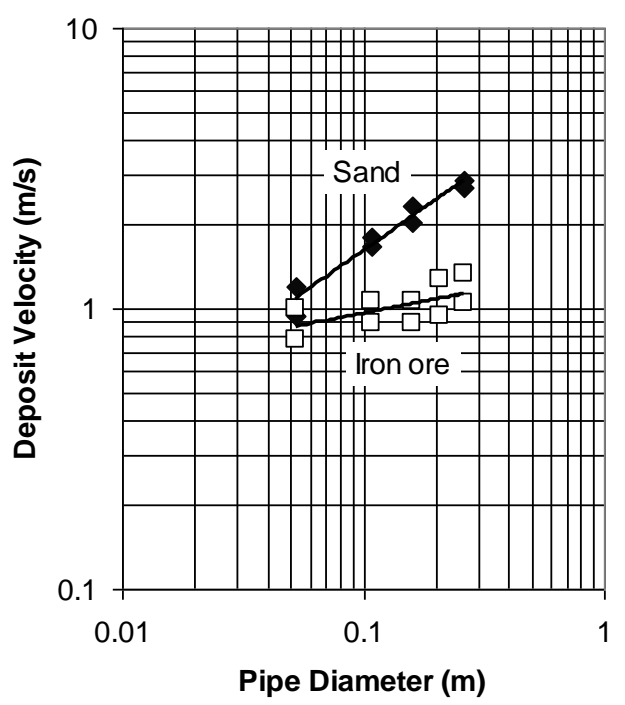

Figure 3 Deposit velocities for wide size distribution sand and iron ore

\subsection{Homogeneous turbulent flow deposition (viscous sub-layer deposition)}

For slurries which are sufficiently fine and viscous and for which deposition occurs within the viscous sublayer in the homogeneous turbulent regime, Thomas (1979a) developed the following equation for the friction velocity at deposition:

$$
\mathrm{V}_{\text {dhom }}^{*}=1.1\left[\mathrm{~g} \eta\left(\rho_{\mathrm{s}}-\rho_{\mathrm{w}}\right) / \rho_{\mathrm{w}}{ }^{2}\right]^{1 / 3}
$$

Now:

$$
\mathrm{V}_{\text {dhom }}^{*}=\mathrm{V}_{\text {dhom }}(\mathrm{f} / 2)^{0.5}
$$

where $\mathrm{f}$ is the Fanning friction factor. Equation (7) was derived on the basis of solid particles in a Newtonian fluid. In the current context $\eta$ is replaced with $\eta_{\mathrm{p}}$ :

$$
\mathrm{V}_{\text {dhom }}=1.1\left[\mathrm{~g} \eta_{\mathrm{pl}}\left(\rho_{\mathrm{s}}-\rho_{\mathrm{w}}\right) / \rho_{\mathrm{w}}{ }^{2}\right]^{1 / 3}(\mathrm{f} / 2)^{-0.5}
$$

\subsection{Laminar flow deposition}

Equation (3) together with Equations (4) and (5) provide a method of predicting the heterogeneous deposit velocity in a slurry pipeline, applicable to prediction of Points A and B in Figure 1, and possibly Point C. Equation (9) provides a method of predicting the minimum deposit velocity, Point $\mathrm{C}$ in Figure 1, based on homogeneous flow deposition.

The authors are unaware of any current definitive method of predicting laminar flow deposition in a pipeline. The difficulty is that slow settling of coarser particles takes place as the slurry travels along the pipeline and so pipeline length is an additional parameter. Thomas (1979b) tested sands in both high viscosity Newtonian fluids and non-Newtonian vehicle slurries. He argued that all particles will have settled after a pipeline length $=\mathrm{DV} / \mathrm{V}_{0}$, i.e. the length to reach full settlement increases with pipe diameter (particles have a greater vertical distance to fall), and velocity $\mathrm{V}$ (the faster the flow velocity the longer the distance travelled before the particles reach the bottom), and also increases the smaller the settling velocity $\mathrm{V}_{0}$. This approach qualitatively described his test loop results with Newtonian vehicles. The situation is more complicated when the vehicle slurry has non-Newtonian properties. Cooke (2002) described laminar flow settling in pipelines in a qualitative sense. He stated that the pressure gradient required to ensure laminar flow operation is between 1,000 and 2,000 Pa/m. Thomas et al. (2004) discussed the matter further. More recently Pullum et al. (2010) studied the situation using CFD techniques but with no easily useable outcome. 


\section{Application to open channel flow}

Section 2 has described the different modes of deposition which occur in pressurised pipe flow. These same modes apply to open channel flow. The premise in this paper is that whether the deposit velocity is due to heterogeneous or homogeneous turbulent deposition, or laminar deposition, the channel automatically adjusts its slope such that the velocity equals the deposit velocity.

There is one major difference between pipe flow and open channel flow. In pipe flow the flow is constrained within the pipe walls. Hence, once some solids deposit out to form a stationary bed, if the head loss gradient is not sufficient to slide the bed along the pipe, then, if flow is maintained, the velocity will increase in the reduced area above the bed causing an increase in head loss gradient. If the pump head is insufficient to meet the increased head loss gradient then the flow rate will decrease, more solids will deposit out and eventually the pipe will block.

With open channel flow the situation is different. If a particular slope is such that the velocity is less than the deposit velocity, coarser solids will drop out, but the remaining flow, being unconstrained, will simply rise up and continue flowing at a reduced concentration. The solids which drop out result in a steeper slope, thereby increasing the velocity until the flowing velocity equals the deposit velocity and equilibrium conditions are attained.

Laminar flow deposition in pipes involves slow settling of the coarser particles and so pipe length is an additional parameter. It was noted in Section 2.4 that there is no definitive method at present to take into account pipeline length. The effect of settling length will be even more complicated in tailings disposal for which there is no clearly defined length.

\section{Development of deposit slope prediction models}

\subsection{Channel shape}

Laboratory and pilot scale flume testing obviously involve a known shape (generally circular) and a measured depth of flow. In contrast, tailings flowing in a channel down a beach slope form their own channel shape. Although the theoretically most hydraulic efficient channel shape is a semi-circle, observed flow channels generally have a width to depth ratio greater than two. Fitton (2007) measured the shape of some dried channel courses and found a typical shape was a parabolic cross section with a width (W) to depth $(\mathrm{H})$ ratio of 5.5. i.e. $\mathrm{W} / \mathrm{H}=5.5$. The current theory assumes this constant shape applies with $\mathrm{W}$, and $\mathrm{H}$, varying with the flow rate and slope.

As is common practice, an equivalent diameter $\mathrm{D}_{\mathrm{eq}}$ is equated to four times the hydraulic radius:

$$
\mathrm{D}_{\text {eq }}=4 \times \text { flow cross sectional area / wetted perimeter }
$$

Based on a parabolic cross section with $\mathrm{W} / \mathrm{H}=5.5$ the following relationships apply.

$$
\begin{gathered}
\text { Area }=2 / 3 \mathrm{WH}=0.121 \mathrm{~W}^{2} \\
\text { Wetted perimeter }=1.082 \mathrm{~W} \\
\quad \mathrm{D}_{\mathrm{eq}}=0.447 \mathrm{~W} \\
\mathrm{~V}=8.264 \mathrm{Q} / \mathrm{W}^{2}
\end{gathered}
$$

\subsection{Turbulent flow pressure gradient}

The method of predicting channel slope for the heterogeneous and homogeneous turbulent flow cases is to predict the relevant deposit velocity using Equations (3) and (9) respectively and then insert this velocity into an equation for turbulent flow pressure gradient and hence obtain the equilibrium slope.

$$
\Delta \mathrm{P} / \mathrm{L}=2 \mathrm{f} \rho_{\mathrm{sl}} \mathrm{V}^{2} / \mathrm{D}_{\mathrm{eq}}
$$

The assumption of homogeneous turbulent flow is considered a reasonable approximation for the relatively fine particle, viscous slurries of interest. Note that even for the relatively coarse slurry of Figure 1, the head 
loss gradients essentially parallel the water curve until transition to laminar flow begins, indicating homogeneous flow at the higher velocities.

An approximate smooth wall Blasius form for homogeneous turbulent flow friction factor, due to Knudsen and Katz (1958), which is better suited to large pipe diameters than the Blasius equation has been adopted.

$$
f=0.046 \mathrm{Re}^{-0.20}
$$

i.e.:

$$
\mathrm{f}=0.046\left(\mathrm{~V} \mathrm{D}_{\mathrm{eq}} \rho_{\mathrm{sl}} / \eta_{\mathrm{pl}}\right)^{-0.20}
$$

The smooth wall assumption could be contentious since many workers assume a channel roughness equivalent to the deposited particle size. Whilst this assumption is reasonable for a narrow size sand in water flow for example, it could be argued that with a wide size distribution tailings, the smaller particles will fill the gaps between the coarser deposited particles, resulting in a relatively smooth surface. Another point to note is that according to Thomas and Wilson (2007), the laminar boundary layer thickens considerably as the transition velocity is approached. Boundary roughness, which is engulfed within the laminar boundary layer, has no effect on the pressure gradient. Because of this thicker boundary layer they found that even for extremely rough pipes with $\mathrm{k} / \mathrm{D}=0.0153$, the pressure gradient approached the smooth pipe value as the velocity approached the transition velocity. The model could be extended in the future to take into account roughness if further work indicates this necessary, but for the present the smooth wall approximation is adopted.

Substituting for $\mathrm{D}_{\text {eq }}$ and V from Equations (13) and (14), into Equation (17):

$$
\mathrm{f}=0.046\left[\left(8.264 \mathrm{Q} / \mathrm{W}^{2}\right)(0.447 \mathrm{~W}) \rho_{\mathrm{sl}} / \eta_{\mathrm{pl}}\right]^{-0.20}
$$

with the number in the square brackets being the Reynolds Number.

or:

$$
\mathrm{f}=0.03542 \mathrm{Q}^{-0.20} \mathrm{~W}^{0.20}\left(\rho_{\mathrm{sl}} / \eta_{\mathrm{pl}}\right)^{-0.20}
$$

Incorporating f from Equation (19) into the previous equation for pressure gradient, Equation (15), we get:

$$
\Delta \mathrm{P} / \mathrm{L}=10.82 \rho_{\mathrm{sl}} \mathrm{Q}^{1.8} / \mathrm{W}^{4.8}\left(\rho_{\mathrm{sl}} / \eta_{\mathrm{pl}}\right)^{-0.20}
$$

\subsection{Heterogeneous turbulent flow}

The heterogeneous deposit velocity in a channel is given by Equations (3), (4) and (5), with D replaced by $D_{\text {eq. }}$. Equating this deposit velocity with the channel velocity of Equation (14) the following expression for channel width $\mathrm{W}$ is obtained:

$$
\mathrm{W}=\left[8.264 \mathrm{Q} / \mathrm{A} / 0.447^{\mathrm{n}}\right]^{1 /(2+\mathrm{n})}
$$

Inserting W from Equation (21) into Equation (20) we get:

$$
\Delta \mathrm{P} / \mathrm{L}=10.82 \rho_{\mathrm{sl}} \mathrm{Q}^{[1.8-4.8 /(2+\mathrm{n})]} /\left(8.264 / \mathrm{A} / 0.447^{\mathrm{n}}\right)^{[4.8 /(2+\mathrm{n})]}\left(\rho_{\mathrm{sl}} / \eta_{\mathrm{pl}}\right)^{-0.20}
$$

Or in terms of channel slope:

$$
\mathrm{S}_{\text {Het }}=1082 \mathrm{Q}^{[1.8-4.8 /(2+\mathrm{n})]} /\left(8.264 / \mathrm{A} / 0.447^{\mathrm{n}}\right)^{[4.8 /(2+\mathrm{n})]}\left(\rho_{\mathrm{sl}} / \eta_{\mathrm{pl}}\right)^{-0.20} / \mathrm{g}
$$

$\mathrm{A}$ and $\mathrm{n}$ are given by previous Equations (4) and (5), with Equation (6).

\subsection{Homogeneous turbulent flow (viscous sub-layer deposition)}

Homogeneous (viscous sub-layer) deposit velocity in pipes was described by Equation (8). Equating V (Equation (14)) and $\mathrm{V}_{\text {dhom }}$ we get:

$$
\mathrm{W}^{2}=8.264 / 1.1 \mathrm{Q}\left[\mathrm{g} \eta_{\mathrm{pl}}\left(\rho_{\mathrm{s}}-\rho_{\mathrm{w}}\right) / \rho_{\mathrm{w}}{ }^{2}\right]^{-1 / 3}(\mathrm{f} / 2)^{0.5}
$$

Or:

$$
\mathrm{W}=2.741 \mathrm{Q}^{0.5}\left[\mathrm{~g} \eta_{\mathrm{pl}}\left(\rho_{\mathrm{s}}-\rho_{\mathrm{w}}\right) / \rho_{\mathrm{w}}{ }^{2}\right]^{-1 / 6}(\mathrm{f} / 2)^{0.25}
$$


Substituting Equation (19) into Equation (25) we get:

$$
\mathrm{W}=1.004 \mathrm{Q}^{0.474}\left[\mathrm{~g} \eta_{\mathrm{pl}}\left(\rho_{\mathrm{s}}-\rho_{\mathrm{w}}\right) / \rho_{\mathrm{w}}{ }^{2}\right]^{-0.175}\left(\rho_{\mathrm{sl}} / \eta_{\mathrm{pl}}\right)^{-0.0526}
$$

Substituting Equation (26) into Equation (20):

$$
\Delta \mathrm{P} / \mathrm{L}=10.61 \rho_{\mathrm{sl}} \mathrm{Q}^{-0.4752}\left[\mathrm{~g} \eta_{\mathrm{pl}}\left(\rho_{\mathrm{s}}-\rho_{\mathrm{w}}\right) / \rho_{\mathrm{w}}{ }^{2}\right]^{0.84}\left(\rho_{\mathrm{sl}} / \eta_{\mathrm{pl}}\right)^{0.052}
$$

Or in terms of percent slope, $\mathrm{S}$ (metres of slurry per $100 \mathrm{~m}$ ):

$$
\mathrm{S}_{\mathrm{hom}}=1061 \mathrm{Q}^{-0.4752}\left[\mathrm{~g} \eta_{\mathrm{pl}}\left(\rho_{\mathrm{s}}-\rho_{\mathrm{w}}\right) / \rho_{\mathrm{w}}{ }^{2}\right]^{0.84}\left(\rho_{\mathrm{sl}} / \eta_{\mathrm{pl}}\right)^{0.052} / \mathrm{g}
$$

Predictions using Equation (28) were compared with measured slopes for large flume turbulent flow data of Fitton (2007) for Sunrise Dam and Cobar tailings. It was found that Equation (28) under-predicted significantly. Analysis of the data comparison indicated that a simple 2.5 multiplying factor improved the situation considerably. This 2.5 factor is incorporated into the final homogeneous turbulent (viscous sublayer) deposition criteria Equation (29).

$$
S_{\text {hom }}=2650 \mathrm{Q}^{-0.4752}\left[\mathrm{~g} \eta_{\mathrm{pl}}\left(\rho_{\mathrm{s}}-\rho_{\mathrm{w}}\right) / \rho_{\mathrm{w}}{ }^{2}\right]^{0.84}\left(\rho_{\mathrm{sl}} / \eta_{\mathrm{pl}}\right)^{0.052} / \mathrm{g}
$$

There is an arguable good reason for the 2.5 factor increase. Thomas' (1979a) theory resulting in Equation (7), was based on solid suspensions in Newtonian fluids, both water and higher viscosity fluids. The Wilson and Thomas (1985) theory of non-Newtonian flow predicts a thickening of the sub-layer as the velocity approaches the transition velocity. The thicker sub-layer means a higher effective Newtonian viscosity which according to Equation (28) would result in a higher value for $\mathrm{S}_{\mathrm{hom}}$.

\subsection{Laminar flow}

In this section we are concerned with the case of laminar flow in a parabolic shaped channel, not with laminar sheet flow. The criteria for laminar flow is set by Equation (1). If $\mathrm{V}$ is less than $\mathrm{V}_{\mathrm{t}}$, the flow is laminar and the laminar slope model applies.

In Section 2.4 it was noted that the authors are unaware of any current definitive method of prediction laminar flow deposition in a pipeline. The problem is that pipeline length is an additional parameter and it is difficult to predict particle settling rates in non-Newtonian slurry flow. The same difficulties occur in the open channel flow case. However, an approximate method has been developed and is presented in this section.

Considering Figure 1 it is apparent that the laminar flow deposition points D, E and F occur at a laminar flow head loss gradient only slightly below the head loss gradient at the relevant transition velocity. This suggests that the open channel, laminar flow head loss gradient at the transition velocity given by Equation (1), will approximate the laminar flow critical deposition slope.

Laminar flow of a Bingham plastic is assumed described by the following explicit approximation to the Buckingham (1921) equation.

$$
\Delta \mathrm{P} / \mathrm{L}=16 \tau_{\mathrm{y}} /\left(3 \mathrm{D}_{\mathrm{eq}}\right)+32 \eta_{\mathrm{pl}} \mathrm{V} / \mathrm{D}_{\mathrm{eq}}^{2}
$$

Replacing $\mathrm{D}_{\mathrm{eq}}$ with Equation (13) and equating $\mathrm{V}$ with $\mathrm{V}_{\mathrm{t}}$ from Equation (1):

$$
\Delta \mathrm{P} / \mathrm{L}=11.93 \tau_{\mathrm{y}} / \mathrm{W}+4000 \eta_{\mathrm{pl}}\left(\tau_{\mathrm{y}} / \rho_{\mathrm{sl}}\right){ }^{0.5} / \mathrm{W}^{2}
$$

Equating $\mathrm{V}$ from Equation (14) with $\mathrm{V}_{\mathrm{t}}$ from Equation (1):

$$
\mathrm{W}^{2}=8.264 \mathrm{Q} /\left[25\left(\tau_{\mathrm{y}} / \rho_{\mathrm{sl}}\right)^{0.5}\right]
$$

Eliminating W from Equation (30) using Equation (31):

$$
\Delta \mathrm{P} / \mathrm{L}=20.75 \tau_{\mathrm{y}}\left(\tau_{\mathrm{y}} / \rho_{\mathrm{sl}}\right)^{0.25} / \mathrm{Q}^{0.5}+12100 \eta_{\mathrm{pl}}\left(\tau_{\mathrm{y}} / \rho_{\mathrm{sl}}\right) / \mathrm{Q}
$$

or slope:

$$
\mathrm{S}_{\mathrm{Lam}}=100\left[20.75 \tau_{\mathrm{y}}\left(\tau_{\mathrm{y}} / \rho_{\mathrm{sl}}\right)^{0.25} / \mathrm{Q}^{0.5}+12100 \eta_{\mathrm{pl}}\left(\tau_{\mathrm{y}} / \rho_{\mathrm{sl}}\right) / \mathrm{Q}\right] / \mathrm{g} / \rho_{\mathrm{s} 1}
$$

Equation (34) predicts the approximate deposit slope when flow is laminar. The approximation involved in this derivation occurs because $\mathrm{V}$ is equated to $\mathrm{V}_{\mathrm{t}}$ and therefore the channel width $\mathrm{W}$ applies to velocity $\mathrm{V}_{\mathrm{t}}$. 
But, as seen in Figure 1, the actual deposit velocity may be considerably less than $V_{t}$, so for the same flow rate, the actual channel width will be larger than the predicted $\mathrm{W}$, thereby resulting in a lower actual head loss gradient at deposition.

An upper limit to the critical slope under laminar flow should be given by the $2,000 \mathrm{~Pa} / \mathrm{m} \mathrm{limit}$ noted for pipe flow in Section 2.4. For a typical tailings concentration of 60\% and solids SG 2.7 (slurry SG 1.6) this upper limit equates to a head loss gradient of $12.7 \mathrm{~m}$ of slurry/100 $\mathrm{m}$ or $12.7 \%$ slope. Or in general:

$$
\mathrm{S}_{\text {LamMax }}=200,000 / \mathrm{g} / \rho_{\mathrm{sl}}
$$

Hence, the deposit slope for laminar flow is equal to that given by Equation (34), or Equation (35), whichever is the least.

\subsection{Combined prediction method}

The slope prediction method involves determining the heterogeneous turbulent slope $\mathrm{S}_{\mathrm{Het}}$ using Equation (23), the homogeneous turbulent slope $S_{\text {hom }}$ using Equation (29), and the laminar slope prediction using Equations (34) and (35), whichever gives the least. The highest prediction for the three types of slurry represents the predicted slope. If the laminar slope prediction is the highest then the flow is laminar.

\section{Comparisons with slope data}

\subsection{Slope data used for comparisons}

- Large flume data of Fitton (2007): The predictions have been compared with experimental data that was collected in two field campaigns conducted at the Peak Gold Mine in Cobar, New South Wales in June 2004 and at the Sunrise Dam Gold Mine near Laverton in Western Australia (WA) in February 2005 (Fitton, 2007). The experimental work was centred on a $10 \mathrm{~m}$ long flume with a half pipe of circular cross section providing the channel shape. The internal surface of the half pipe was coated with sand. During the Cobar programme two different sized half pipes were used; radial dimensions were 207 and $180 \mathrm{~mm}$ respectively. During the Sunrise Dam campaign only one pipe was used, which had a radius of $170 \mathrm{~mm}$. In both experimental campaigns the slope of the flume could be adjusted from $0 \%$ (horizontal) to $7 \%$. Tailings slurry was run down the flume at various flow rates and concentrations, with a trial and error approach used to determine the channel slope at which particle deposition and hydraulic erosion was in equilibrium for each discharge scenario. Rheological analysis was done with a viscometer.

- ATC Williams data set: The ATC Williams data set contains real beach slopes measured at 16 real tailings beaches. This data has been collected by ATC Williams at a number of mine sites over the past 28 years.

- Stack Data: Beach slopes on the tailings stacks at the Peak Mine in Cobar, NSW and the Sunrise Dam Gold Mine in WA were measured at the upper, middle and lower thirds of the beach (Fitton, 2007). The slurry discharge parameters were also noted.

- Alluvial fan data: The alluvial fan data was gathered in a series of laboratory experiments that were reported in a paper by Whipple et al. (1998). Dilute sand/water mixtures of various flow rates and concentrations were discharged across a flat surface and over a weir to create alluvial fans of about $5 \mathrm{~m}$ radius. Slopes were measured.

\subsection{Plot of predicted slope against observed slope for all the data}

The new beach slope model was used to predict the beach or channel slopes that were observed in these four data sets. A plot of the predicted slopes against the observed slopes is presented as Figure 4. 


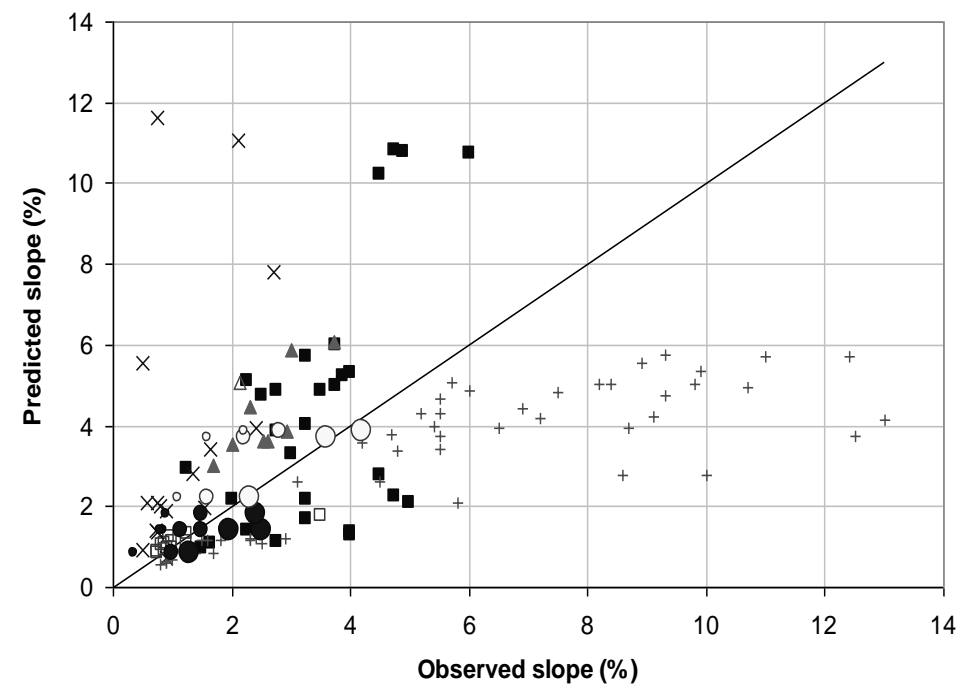

- Sunrise Dam flume - Laminar

- Sunrise Dam flume - Turbulent

$\Delta$ Cobar flume - Laminar

$\triangle$ Cobar flume - Turbulent

$\times$ ATC data

+ Alluvial fan data

- Sunrise Dam Stack - Upper third

- Sunrise Dam stack - Middle Third

- Sunrise Dam stack - Lower third

o Cobar stack - Upper third

○ Cobar stack - Middle third

- Cobar stack - Lower third

— Ideal 1 to 1 Fit

Figure 4 Fit plot - Thomas Fitton beach slope model (all data)

In general, the agreement is satisfactory although the alluvial fan data are not well predicted. The alluvial fan under-prediction is probably because the current theory assumes a smooth wall whereas the alluvial fan data refer to granular suspensions with no fines present. In this case the hydraulic roughness is probably considerably greater than for a smooth wall and consequently the pressure gradient and predicted slope would be higher than predicted using the smooth wall basis.

Note: Fitton (2007) also tested glass particles in various non-Newtonian fluids in a $50 \mathrm{~mm}$ diameter flume. The solids concentrations tested were extremely low, typically only a few percent. The current prediction method severely over-predicts this small flume data and the comparisons are not shown in Figure 4. The model could be altered to incorporate the effect of such low concentrations but these concentrations are considered so unrealistic for 'real' tailings disposal that this additional complexity is considered unwarranted.

\subsection{Plot of predicted slope against observed slope for real tailings beach data only}

In Figure 5, the data comparison is limited to the real tailings beach data for Sunrise Dam and Cobar stacks and the ATC Williams data. Four ATC data points are severely over-predicted but the rest of the data are reasonably well predicted.

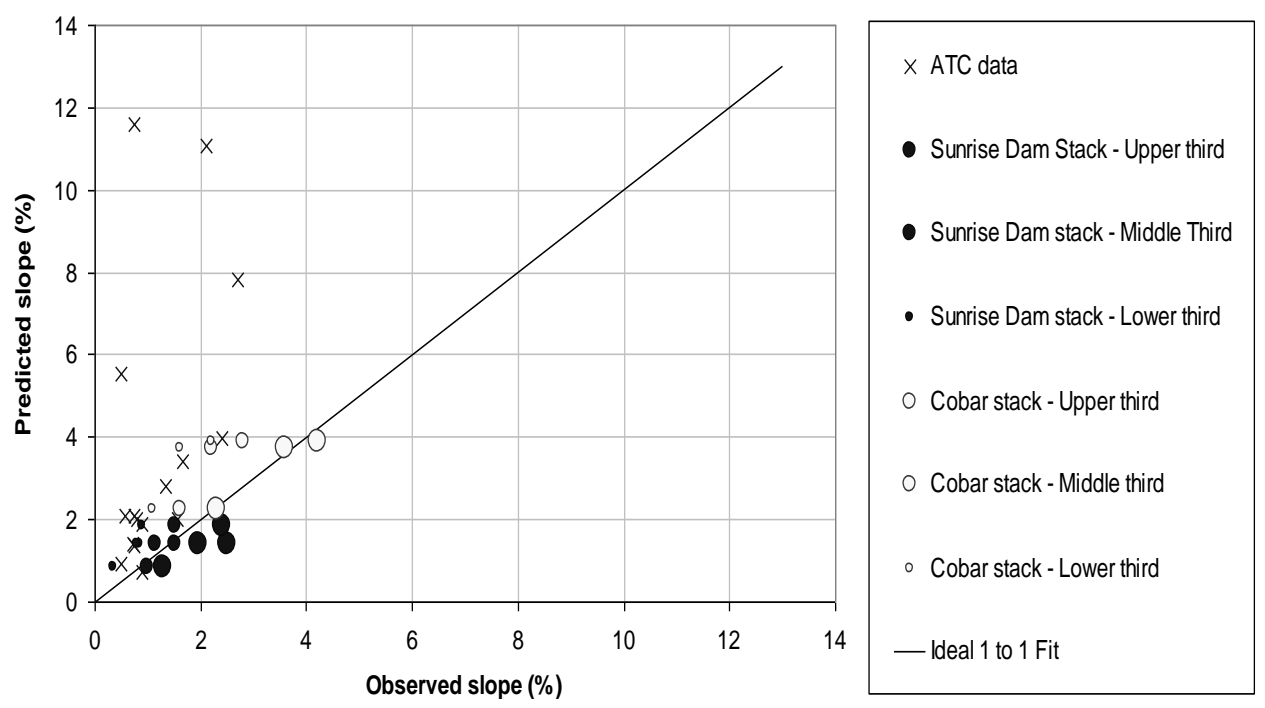

Figure 5 Thomas Fitton beach slope model (real tailings beaches) 


\section{Conclusions}

A new slope prediction model has been developed from a physical basis based on slurry pipeline prediction methods. It is apparent from Figures 4 and 5 that the new beach slope model generally makes reasonable slope predictions.

\section{$7 \quad$ Nomenclature}

A' Constant in Equation (2).

A Constant in Equations (3) and (4).

D Pipe diameter (m).

$D_{\text {eq }} \quad$ Equivalent pipe diameter $(m)$.

d Representative particle size (m).

$\mathrm{d}_{80} \quad$ Particle size for which $80 \%$ of particles are finer (m).

$\mathrm{d}_{50} \quad$ Median particle size (m).

$d_{20} \quad$ Particle size for which $20 \%$ of particles are finer $(m)$.

f Fanning friction factor.

g Gravitational constant $\left(\mathrm{m} / \mathrm{s}^{2}\right)$.

$\mathrm{H}$ Depth of flow stream in channel (m).

$\mathrm{n} \quad$ Exponent in Equations (2), (3) and (5).

Q Flow rate $\left(\mathrm{m}^{3} / \mathrm{s}\right)$.

Re Reynolds number, Equation (17).

S Slope of channel (\%).

$S_{\text {het }} \quad$ Equilibrium slope of channel for heterogeneous turbulent flow, Equation (23).

$S_{\text {hom }} \quad$ Equilibrium slope of channel for homogeneous turbulent flow, Equation (28).

$\mathrm{S}_{\mathrm{lam}} \quad$ Equilibrium slope of channel for laminar flow, Equation (34).

$S_{\text {lam.max }}$ Upper limit for equilibrium slope of channel in laminar flow, Equation (35).

$\mathrm{V} \quad$ Average velocity in channel $(\mathrm{m} / \mathrm{s})$.

$\mathrm{V}^{*}$ dhom Friction velocity at deposition for homogeneous turbulent flow, Equation (7) $(\mathrm{m} / \mathrm{s})$.

$\mathrm{V}_{0} \quad$ Settling velocity of a particle in quiescent fluid $(\mathrm{m} / \mathrm{s})$.

$\mathrm{V}_{\text {dhet }}$ Deposit velocity in heterogeneous turbulent flow, Equation (3) $(\mathrm{m} / \mathrm{s})$.

$\mathrm{V}_{\text {dhom }}$ Deposit velocity in homogeneous turbulent flow, Equation (9) $(\mathrm{m} / \mathrm{s})$.

$\mathrm{V}_{\mathrm{t}} \quad$ Transition velocity between laminar and turbulent flow, Equation (1) $(\mathrm{m} / \mathrm{s})$.

W Width of channel flow (m).

$\Delta \mathrm{P} / \mathrm{L} \quad$ Pressure gradient $(\mathrm{kPa} / \mathrm{km})$.

$\eta_{\mathrm{pl}} \quad$ Bingham plastic viscosity based on highest shear rate data of flow curve (Pa.s).

$\rho_{\mathrm{s}} \quad$ Density of solids $\left(\mathrm{kg} / \mathrm{m}^{3}\right)$.

$\rho_{\mathrm{sl}} \quad$ Density of slurry $\left(\mathrm{kg} / \mathrm{m}^{3}\right)$.

$\rho_{\mathrm{w}} \quad$ Density of water or fluid $\left(\mathrm{kg} / \mathrm{m}^{3}\right)$.

$\tau_{\mathrm{y}} \quad$ Bingham plastic yield stress based on highest shear rate data of flow curve $(\mathrm{Pa})$. 


\section{References}

Buckingham, E. (1921) On plastic flow through capillary tubes, ASTM Proceedings, Vol. 21, pp. 1154-1156.

Cooke, R. (2002) Laminar flow settling: the potential for unexpected problems, in Proceedings Hydrotransport 15 Conference, Banff, Canada.

Durand, R. (1953) Minnesota International Hydraulics Convention, in Proceedings International Association for Hydraulic Research, Lisbon, Portugal, pp. 89-103.

Fitton, T. (2007) Tailings beach slope prediction, PhD Thesis, RMIT University, Melbourne, Australia.

Houman, J. and Johnson, G. (2002) High density disposal of co-thickened Kimberlite slurry using positive displacement pumps - a case study, in Proceedings Hydrotransport 15 Conference, Banff, Canada.

Knudsen, J.G. and Katz, D.L. (1958) Fluid Dynamics and Heat Transfer, McGraw-Hill, New York.

McPhail, G.I. (1994) Prediction of the beaching characteristics of hydraulically placed tailings, PhD thesis, University of Witwatersrand, South Africa.

Pullum, L., Graham, L. and Wu, J. (2010) Bed establishment lengths under laminar flow, in Proceedings Hydrotransport 18 Conference, Rio de Janeiro, Brazil.

Schriek, W., Smith, L.G., Haas, D.B. and Husband, W.H.W. (1973a) Experimental studies on the transport of two different sands in water in 2, 4, 6, 8, 10 and 12 inch pipelines, Saskatchewan Research Council, Canada.

Schriek, W., Smith, L.G., Haas, D.B. and Husband, W.H.W. (1973b) Experimental studies on the hydraulic transport of iron ore, Saskatchewan Research Council, Canada.

Thomas, A.D. (1974) Unpublished data, M.D. Research Company, Sydney, Australia.

Thomas, A.D. (1979a) Predicting the deposit velocity for horizontal turbulent pipe flow of slurries, International Journal Multiphase Flow, Pergamon/Elsevier, Vol. 5, pp. 113-129.

Thomas, A.D. (1979b) Pipelining of coarse coal as a stabilized slurry - another viewpoint, in Proceedings 4th International Technical Conference on Slurry Transportation, Las Vegas, USA.

Thomas, A.D. and Wilson, K.C. (2007) Rough-wall and turbulent transition analyses for Bingham plastics, in Proceedings Hydrotransport 17 Conference, Cape Town, South Africa.

Thomas, A.D., Pullum, L. and Wilson, K.C. (2004) Stabilised laminar slurry flow: review, trends and prognosis, in Proceedings Hydrotransport 16 Conference, Santiago, Chile.

Williams, M.P.A. and Meynink, W.J.C. (1986) Tailings beach slopes, Workshop on Mine Tailings Disposal, University of Queensland, Brisbane, Australia.

Wilson, K.C. and Judge, D.G. (1976) New techniques for the scale-up of pilot plant results to coal slurry pipelines, in Proceedings International Symposium on Freight Pipelines, Washington DC, USA.

Wilson, K.C. and Thomas, A.D. (1985) A new analysis of the turbulent flow of non-Newtonian fluids, Canadian Journal of Chemical Engineering, Vol. 63, pp. 539-546.

Wilson, K.C. and Thomas, A.D. (2006) Analytic model of laminar-turbulent transition for Bingham plastics, Canadian Journal of Chemical Engineering, October 2006, Canada.

Whipple, K., Parker, G., Paola, C. and Mohrig, D. (1998) Channel Dynamics, Sediment Transport, and the Slope of Alluvial Fans: Experimental Study, Journal of Geology, Vol. 106, No. 6, pp. 677-693. 